\title{
Comparison of the nicotine content of tobacco used in bidis and conventional cigarettes
}

\author{
Jennifer L Malson, Kristi Sims, Ram Murty, Wallace B Pickworth
}

\begin{abstract}
Objective-To compare the nicotine content of 12 unfiltered brands of bidi cigarettes (hand rolled cigarettes imported from India) with 8 popular brands of filtered and unfiltered US and conventional cigarettes from India.

Main outcome measures-Identical laboratory procedures were used to determine nicotine content (in duplicate) and physical characteristics.

Results-The nicotine concentration in the tobacco of bidi cigarettes $(21.2 \mathrm{mg} / \mathrm{g})$ was significantly greater than the tobacco from the commercial filtered $(16.3 \mathrm{mg} / \mathrm{g})$ and unfiltered cigarettes $(13.5 \mathrm{mg} / \mathrm{g})$. Conclusions-Bidi cigarettes contain higher concentrations of nicotine than conventional cigarettes. Therefore, it is logical to presume that bidi smokers are at risk of becoming nicotine dependent. These findings belie a popular belief among US teens that bidis are a safe alternative to commercial cigarettes.

(Tobacco Control 2001;10:181-183)
\end{abstract}

Keywords: bidis; beedies; youth

A recent estimate of smoking initiation indicates that worldwide between 82000 and 99000 young people begin smoking each day. ${ }^{1}$ In the USA, about 3000 teenagers begin smoking daily, nearly one million a year. ${ }^{2}$ Despite efforts aimed at decreasing teenage smoking, there has been an increase in smoking among that age group. ${ }^{3}$ Although many US teenage smokers prefer commercial cigarette brands such as Marlboro and Camels, ${ }^{4}$ others are attracted to alternative tobacco products such as bidis, cloves, and additive-free, natural tobacco cigarettes. ${ }^{56}$ In a national study, $2.4-5.0 \%$ of adolescents were using bidi cigarettes. ${ }^{5}$ A convenience sample from Boston indicates a higher prevalence with $16 \%$ of adolescents as current users. ${ }^{6}$ There is a notion among teenage smokers that alternative cigarettes have less health risks than conventional cigarettes. ${ }^{6}$

Bidis, an alternative type of cigarette, are manufactured in India and exported worldwide. Bidis consist of finely ground, sun dried tobacco rolled in a brown, tendu leaf. The leaf is from a broad leafed plant (Diospyrus melanoxylon or Diospyrus ebemum) native to India. Bidi cigarettes are similar in appearance to hand rolled marijuana cigarettes or joints. Most bidis are $60 \mathrm{~mm}$ in length, although some are $100 \mathrm{~mm}$. Most bidis are unfiltered, although a few are filtered. Highly flavoured varieties of bidi cigarettes, including cherry, menthol, cinnamon, strawberry, vanilla, and raspberry, are widely available in retail outlets and on the internet. Flavour additives may partially account for the popularity of bidis among young consumers. Other explanations for bidi popularity among teens are that they are less expensive than commercially available cigarettes, they easily accessible, and they are trendy. ${ }^{67}$

Toxicological and epidemiological reports indicate that the smoke of bidis, like commercial cigarettes and cheroots, contains phenol, hydrogen cyanide, and benzo(a)pyrenes $^{8}$ and total particulate matter, a measure directly related to the amount of carcinogenic material. ${ }^{9}$ Nair and colleagues identified carcinogenic tobacco specific nitrosamines from the smoke of bidis in concentrations similar to those of commercial cigarettes. ${ }^{10}$ Bidis also deliver considerable amounts of carbon monoxide. Blood carboxyhaemoglobin concentrations were raised in bidi smokers ${ }^{11}$ and the concentrations of carboxyhaemoglobin were correlated with self-assessed degree of smoke inhalation and number of bidis. ${ }^{12}$ Compared to the smoke of an unfiltered US cigarette, bidi smoke contained more carbon monoxide, ammonia, hydrogen cyanide, phenol, volatile phenols, benz(a)anthracene, and benzo(a)pyrene. ${ }^{13}{ }^{14}$ These studies indicate that bidis are hazardous to health. Further, the delivery of nicotine in sufficient quantities initiates and sustains dependence, ${ }^{15}$ which perpetuates the delivery of toxic components of smoke to the user.

Although some studies have been conducted to establish nicotine and tar levels of bidis on a standard smoking machine, the nicotine concentration of tobacco in bidis has not been examined. ${ }^{13}$ Given the large variety of bidi cigarettes available, it is uncertain how applicable the results of previous studies are to the products currently available. In the present study, the nicotine content and other physical characteristics of 12 popular brands of unfiltered bidi cigarettes, three Indian and four US commercial filtered cigarettes, and a non-filtered "additive-free" cigarette (American Spirit) were compared.

\section{Methods}

Commercial cigarettes and bidis (tables 1 and 2) were obtained from local retail outlets for the study. Tobacco weights of the cigarettes were based on an average of 10 cigarettes, while the tobacco weights of the bidis were based on an average of 20 bidis. For each brand of bidi cigarette, the tobacco was removed from 
Table 1 Characteristics of bidi cigarettes

\begin{tabular}{|c|c|c|c|c|}
\hline & $\begin{array}{l}\text { Average } \\
\text { cigarette weight } \\
\text { (mg) }\end{array}$ & $\begin{array}{l}\text { Average } \\
\text { tobacco weight } \\
(m g)\end{array}$ & $\begin{array}{l}\text { Average } \\
\text { nicotine/rod } \\
\text { (mg) }\end{array}$ & $\begin{array}{l}\text { Nicotine } \\
(\mathrm{mg} / \mathrm{g})^{\star}\end{array}$ \\
\hline Irie Cherry & 447.1 & 173.2 & 3.6 & 20.820 .1 \\
\hline Irie Menthol & 456.6 & 211.4 & 3.3 & 15.715 .3 \\
\hline Irie Cinnamon & 432.0 & 179.1 & 3.5 & $18.8 \quad 19.9$ \\
\hline Irie Strawberry & 449.0 & 219.3 & 4.5 & 20.420 .7 \\
\hline Irie Vanilla & 441.0 & 197.4 & 3.8 & 19.619 .1 \\
\hline Sher Bidis 100 & 1024.8 & 466.4 & 12.4 & 27.027 .1 \\
\hline Sher Bidis & 368.1 & 166.2 & 3.9 & 23.024 .5 \\
\hline Shiv Sigar Raspberry & 467.9 & 200.4 & 4.0 & 20.120 .3 \\
\hline Shiv Sigar Chocolate 100 & 576.3 & 242.5 & 5.7 & 23.323 .6 \\
\hline Kailis Bidi Menthol & 503.4 & 181.1 & 3.4 & 18.718 .8 \\
\hline Kailis Bidi Strawberry & 552.8 & 190.6 & 4.0 & 20.921 .4 \\
\hline Guru Bidis & 355.5 & 155.5 & 3.9 & $24.8 \quad 25.7$ \\
\hline Overall averages & 506.2 & 215.3 & 4.7 & 21.2 \\
\hline
\end{tabular}

^Analyses were run in duplicate, results are shown for both determinations

Table 2 Characteristics of commercial cigarettes

\begin{tabular}{lcclrl}
\hline & $\begin{array}{l}\text { Average } \\
\text { cigarette weight } \\
(\mathrm{mg})\end{array}$ & $\begin{array}{l}\text { Average } \\
\text { tobacco weight } \\
(\mathrm{mg})\end{array}$ & $\begin{array}{l}\text { Average } \\
\text { nicotine/rod } \\
(\mathrm{mg})\end{array}$ & $\begin{array}{l}\text { Nicotine } \\
(\mathrm{mg} / \mathrm{g})\end{array}$ \\
\hline Unfiltered & 1130.5 & 1064.4 & 17.7 & 16.2 & 17.0 \\
$\quad \begin{array}{l}\text { American Spirit (US) } \\
\text { Golcondo (I) }\end{array}$ & 823.6 & 772.4 & 9.0 & 11.4 & 11.8 \\
$\quad$ Charminar (I) & 796.5 & 745.1 & 9.2 & 12.5 & 12.2 \\
Overall averages & $\mathbf{9 1 6 . 9}$ & $\mathbf{8 6 0 . 6}$ & $\mathbf{1 2 . 0}$ & $\mathbf{1 3 . 5}$ & \\
& & & & & \\
Filtered & 921.8 & 710.0 & 12.0 & 17.0 & 16.8 \\
$\quad$ Marlboro (US) & 938.0 & 715.6 & 14.0 & 19.5 & 19.5 \\
Newport Menthol (US) & 927.8 & 716.3 & 12.1 & 16.7 & 17.1 \\
Camel (US) & 915.5 & 710.9 & 14.0 & 19.5 & 19.9 \\
$\quad$ Kool Menthol (US) & 992.1 & 840.0 & 7.0 & 8.3 & 8.2 \\
$\quad$ Gold Flake (I) & $\mathbf{9 3 9 . 0}$ & $\mathbf{7 3 8 . 6}$ & $\mathbf{1 1 . 8}$ & $\mathbf{1 6 . 3}$ & \\
Overall averages & & & &
\end{tabular}

US, US brand; I, Indian brand.

the wrapping, weighed, and pooled for chemical analysis (in duplicate). Two samples were taken from the pooled resource and analysed. These results were averaged for an overall total.

The amount of nicotine was determined using a Hewlett Packard 6890 gas chromatograph equipped with an autosampler and a flame ionisation detector using methods described elsewhere. ${ }^{16}{ }^{17}$ Briefly, a Hewlett Packard HP1 methyl silicon column $(0.53 \mathrm{~mm}$ inner diameter, $0.88 \mu \mathrm{m}$ film thickness, $30 \mathrm{~m}$ length) was used. The injector was set at $300^{\circ} \mathrm{C}$, using a $1 \mu \mathrm{l}$ pulsed splitless injection. The oven was set isothermally at $120^{\circ} \mathrm{C}$ and the detector was set at $250^{\circ} \mathrm{C}$. Helium $(7.6 \mathrm{ml} /$ min) was used as the carrier gas. This method has a limit of detection of $350 \mathrm{pg}$ and a limit of quantitation of $4.5 \mathrm{ng}$. Linearity was established from $3.3 \mu \mathrm{g} / \mathrm{ml}$ to $480 \mu \mathrm{g} / \mathrm{ml}$, and the range was from $4.5 \mu \mathrm{g} / \mathrm{ml}$ to $435 \mu \mathrm{g} / \mathrm{ml}$.

The gas chromatography samples were prepared by weighing $100 \mathrm{mg}$ of tobacco and adding $10 \mathrm{ml}$ of $1 \%$ potassium hydroxide $(\mathrm{KOH})$ in methanol. The solutions were sonicated for eight hours, keeping the solution temperature below $45^{\circ} \mathrm{C}$. After sonication, the samples were centrifuged for five minutes. The supernatant was then used for gas chromatography analysis. Nicotine standards were prepared in $1 \% \mathrm{KOH}$ in methanol. A calibration curve was constructed using linear regression of peak area versus concentration of the standards. The amount of nicotine in the samples was calculated from the calibration curve. Concentrations of nicotine were statistically compared using the Student $t$ test.

\section{Results}

As shown in table 1, the 12 brands of bidi cigarettes had an average weight of $506 \mathrm{mg}$ per cigarette. The tobacco weight averaged $215 \mathrm{mg}$. The tendu leaf wrapping accounted for $51.2-65.5 \%$ of the total cigarette weight. This supports prior findings that the tendu leaf is responsible for, on average, $60 \%$ of the total weight of a bidi. ${ }^{14}$ The nicotine concentration of the tobacco from the bidi cigarettes averaged $21.2 \mathrm{mg} / \mathrm{g}$ compared to the tobacco from filtered and unfiltered commercial cigarettes (table 2) that averaged $16.3 \mathrm{mg} / \mathrm{g}$ and $13.5 \mathrm{mg} / \mathrm{g}$, respectively. Statistical comparisons of the nicotine concentrations revealed that the bidis contained tobacco significantly more concentrated in nicotine than the filtered $(\mathrm{t}(15)=2.59, \mathrm{p}=0.02)$ and the unfiltered $(t(13)=3.87, \quad p=0.002)$ cigarettes. The weight of commercial filtered and unfiltered commercial cigarettes averaged $940 \mathrm{mg}$ and $917 \mathrm{mg}$, respectively. The tobacco content of commercial filtered and unfiltered commercial cigarettes averaged $739 \mathrm{mg}$ and $861 \mathrm{mg}$, respectively. Commercial cigarettes in the present study contained similar concentrations and amounts of nicotine to those reported in other studies. ${ }^{18}$ The overall average nicotine concentration of bidis $(21.2 \mathrm{mg} / \mathrm{g})$ was larger than any of the commercial brands of cigarettes (filtered or unfiltered). However, Irie Menthol bidis had an average nicotine concentration $(15.5 \mathrm{mg} / \mathrm{g})$ that was lower than American Spirit and several filtered commercial brands.

\section{Discussion}

The bidis tested contained less tobacco than other cigarettes. However, their tobacco contains significantly higher concentrations of nicotine than the tobacco of commercial cigarettes. One measure of the addictive potential of tobacco products is the amount of nicotine available to the consumer. Benowitz and Henningfield have theorised that a minimum threshold level of nicotine delivery is necessary to initiate and sustain dependence..$^{15}$ Although cigarette manufacturers describe their products as "ultra lights," "lights" and "full flavor" cigarettes, the nicotine content of the tobacco rods are similar. ${ }^{18}$ Cigarette smokers can titrate the amount of nicotine they obtain from a cigarette by changing their smoking behaviour. ${ }^{19} 20$ Smokers may titrate the amount of nicotine delivery from bidis just as they adjust the nicotine delivery from commercial cigarettes. However, preliminary results from a clinical study that measured plasma nicotine concentrations indicate that higher concentrations of nicotine were seen after smoking bidi cigarettes (Pickworth et al, 11th World Congress on Tobacco OR Health, abstract, 2000, unpublished data).

Bidi cigarettes are smoked differently than commercial cigarettes. For example, bidi cigarettes must be re-lit several times because they self-extinguish ${ }^{21}$ if they are not puffed at least two times a minute. ${ }^{14}$ The time to smoke and number of puffs were significantly greater while smoking a Sher bidi than commercial cigarette smoking in a clinical study (Malson 
and Stanton, Eastern Psychological Association, abstract, 2000, unpublished data). Finally, there is less air dilution through the tendu leaf than conventional cigarettes. ${ }^{7}$ Low combustibility forces a smoker to inhale more deeply resulting in greater delivery of carbon monoxide, nicotine, and other components of tobacco smoke. ${ }^{813}$ All of these factors may exaggerate the health risks associated with nicotine and other components of bidi smoke.

In addition to the well documented accounts of the toxic chemicals in bidi smoke, their delivery of nicotine poses a risk for the development of dependence. All smoked tobacco products have a potential abuse liability and the ability to initiate and sustain nicotine dependence. ${ }^{22}$ Even rapid delivery nicotine replacement products such as the gum and the nasal spray have a potential for abuse. ${ }^{23}$ The dependence potential of bidis is further evident in India where bidi smoking accounts for $40 \%$ of tobacco consumption. ${ }^{24}$

A recent study of urban US youth indicated that $40 \%$ had smoked bidis at least once and $16 \%$ were current users. ${ }^{6}$ There were no significant differences between race, ethnicity, and sex. "Better taste" was the reason most often endorsed for preference of bidis over commercial cigarettes. ${ }^{6}$ Highly flavoured smokeless tobacco products tend to appeal to a youthful market. ${ }^{25}$ The flavouring additives may mask the harshness of the concentrated nicotine in the bidis and may allow for deeper inhalation while smoking. Teens are drawn to bidi cigarettes because they are highly flavoured and marketed as alternative products. Furthermore, teens are also attracted to bidi cigarettes because they are trendy, cheaper, and easier to buy than commercial cigarettes. $^{56}$

Our interest in this research was to examine the nicotine concentrations of tobacco of several (12) popular brands of bidis. Because of the inherent variability in the production of a hand rolled tobacco product, another study could be conducted to determine the tobacco content and nicotine concentration within a single brand of bidi cigarettes. Other studies are needed to demonstrate the effect of bidi smoking on plasma concentrations of nicotine, exhaled carbon monoxide, and other physiologic effects.

In summary, results show that the nicotine concentration of the tobacco of bidi cigarettes is higher than the concentration of nicotine in commercial cigarettes. As a result of the nicotine exposure, bidi smokers are at risk for tobacco dependence. These findings refute the notion among US teens that bidi smoking is a safe alternative to commercial cigarettes.

1 The World Bank. Curbing the epidemic: governments and the economics of tobacco control. Washington, DC: World Bank 1999. http://www.globalink.org/tobacco/wb

2 Kessler DA. Nicotine addiction in young people. $N$ Engl f Med 1995;333:186-9.

3 US Department of Health and Human Services. National household survey on drug abuse: population estimates, 1998. household survey on drug abuse: population estimates, 1998.
Rockville, Maryland: Substance Abuse and Mental Health
Services Administration, 1999.

4 Cummings KM, Hyland A, Pechacek TF, et al. Comparison of recent trends in adolescent and adult cigarette smoking
behaviour and brand preferences. Tobacco Control 1997; 6(suppl 2):S31-7.

\section{What this paper adds}

Bidis are hand rolled cigarettes from India that are popular among US teenagers. Some adolescents believe bidis are healthy alternatives to conventional cigarettes. The nicotine content and delivery characteristics from bidis have not been published. These are important determinants of abuse liability.

The present study showed that the tobacco in bidi cigarettes has a higher concentration of nicotine than the tobacco in filtered and unfiltered commercial cigarettes. Like conventional cigarettes, bidi cigarettes have the potential to initiate and sustain tobacco dependence. This belies the notion of US teenagers that bidis are a safe alternative to cigarettes.

5 Centers for Disease Control and Prevention. Tobacco use among middle and high school students-United States, 1999. MMWR Morb Mortal Wkly Rep 2000;49:49-53.

6 Centers for Disease Control and Prevention. Bidi use among urban youth-Massachusetts, March-April 1999. MMWR Morb Mortal Wkly Rep 1999;48:796-7.

7 Fisher L. Bidis-the latest trend in US teen tobacco use. Cancer Causes and Control 2000;11:577-8.

8 Pakhale SS, Jayant K, Bhide SV. Chemical analysis of smoke of Indian cigarettes, bidis and other indigenous forms of smoking-levels of steam-volatile phenol, hydrogen cyanide and benzo(a)pyrene. Indian $\mathcal{F}$ Chest Dis Allied Sci 1990;32:75-81.

9 Mishra UC, Shaikh GN. Total particulate matter in cigarette and bidi smoke. Sci Total Environ 1984;37:21322 .

10 Nair J, Pakhale SS, Bhide SV. Carcinogenic tobacco-specific nitrosamines in Indian tobacco products. Food Chem Toxicol 1989;27:751-3.

11 Behera D, Dash S, Dinakar M. Blood carboxyhaemoglobin levels in Indian bidi and cigarette smokers. Respiration 1991;58:26-8.

12 Behera D, Dash S, Dinakar M. Correlation of smoking behaviour and blood carboxyhaemoglobin in bidi and cigarette smokers. Indian 7 Chest Dis Allied Sci 1991; 33:43-6.

13 Hoffmann D, Sanghvi LD, Wynder EL. Comparative chemical analysis of Indian bidi and American cigarette smoke. Int $\mathcal{F}$ Cancer 1974;14:49-53.

14 Rahman M, Fukui T. Bidi smoking and health. Public Health 2000;114:123-7.

15 Benowitz NL, Henningfield JE. Establishing a nicotine threshold for addiction-the implications for tobacco regulation. N Engl f Med 1994;331:123-5.

16 Madsen JP, Bush LP, Gay SL. Effects of curing on polyamine content of leaves of nicotiana tabacum- $L$ genotypes with different alkaloid levels. F Agric Food Chem 1985;33:1182-5.

17 Severson RF, McDuffie KL, Arrendale RF, et al. Rapid method for the analysis of tobacco nicotine alkaloids. 7 Chromatogr 1981;211:111-21.

18 Massachusetts Department of Public Health. 1997 Cigarette nicotine disclosure report. Boston: Massachusetts Department of Public Health, 1998

19 Herning RI, Jones RT, Benowitz NL, et al. How a cigarette is smoked determines blood nicotine levels. Clin Pharmacol Ther 1983;33:84-90.

20 Benowitz NL, Hall SM, Herning RI, et al. Smokers of lowyield cigarettes do not consume less nicotine. $N$ Engl F Med 1983;309:139-42.

21 Yadav JS, Thakur S. Cytogenetic damage in bidi smokers. Nic Tob Resh 2000;2:97-103.

22 US Department of Health and Human Services. The health consequences of smoking: nicotine addiction. A report of the Service, Centers for Disease Control, Office on Smoking and Health, 1988. (DHHS Publication No (CDC) 88-8406.)

23 Fant RV, Pickworth WB, Henningfield JE. The addictive effects of nicotine are related to the speed of delivery. In: Opitz K, ed. Nicotine as a therapeutic agent, immunity and the environment, vol 10. Stuttgart: Gustav-Fisher, 1997:5361

24 World Health Organization. Tobacco or health: a global status report. Geneva: WHO, 1997.

25 Fant RV, Henningfield JE, Nelson RA, et al. Pharmacokinetics and pharmacodynamics of moist snuff in humans.
Tobacco Control 1999;8:387-92. 